\title{
A CLÁUSULA ARBITRAL COMPROMISSÓRIA COMO MEIO DE RESOLUÇÃO DE CONFLITOS NOS CONTRATOS DE BUILT TO SUIT
}

\author{
Mayra Rosane Melo ${ }^{1}$ \\ Jamile Gonçalves Calissi ${ }^{2}$ \\ Renato Zanolla Montefusco ${ }^{3}$
}

\begin{abstract}
RESUMO: O negócio jurídico na modalidade de built to suit, tema que se pretende desenvolver neste presente trabalho, baseia-se em contratos empresariais complexos, que regulamentam uma operação diferenciada e estabelece inúmeros direitos e obrigações livremente pactuadas entre as partes. Esse tipo de operação, já amplamente difundido no exterior, passou a ser reconhecido no Brasil através da necessidade de grandes empreendimentos se instalarem no país devido ao aquecimento e pleno desenvolvimento do setor imobiliário. Por se tratar de um negócio jurídico complexo e celebração contratual se pautar na autonomia privada das partes. O presente trabalho objetiva demonstrar a legalidade da inserção de cláusula de compromisso arbitral nos contratos de built to suit como forma de garantir a segurança jurídica nos negócios, principalmente se considerarmos pedidos de revisão das bases contratuais em virtude de fatos supervenientes, como é o caso da pandemia do Covid-19 ou de outras crises econômicas. Acredita-se que a arbitragem como meio de resolução de conflitos acarretará maior segurança nas particularidades do negócio, prevalecendo às disposições contratuais pré-estabelecidas estabelecidas.
\end{abstract}

PALAVRAS-CHAVE: Negócio jurídico; autonomia da vontade das partes; arbitragem; contratos; built to suit.

\section{THE ARBITRATION ARBITRATION CLAUSE AS A MEANS OF RESOLVING CONFLICTS IN BUILT TO SUIT CONTRACTS}

\footnotetext{
${ }^{1}$ Mestranda em Direito e gestão de conflitos pela Universidade de Araraquara - Uniara. Especialista em Direito empresarial pela Fundação Getúlio Vargas RJ e em Direito Processual Civil pelo Centro Universitário Unifafibe. Graduação em Direito pelo Centro Universitário Unifafibe (2014). Advogada e Coordenadora do Núcleo de Práticas Jurídicas do Centro Universitário Unifafibe

${ }^{2}$ Doutorado e Mestrado (Bolsista Integral CAPES) em Direito Constitucional pela Faculdade de Direito de Bauru (CEUB-ITE). MBA em Gestão Empresarial pela Fundação Getúlio Vargas. Graduação em Direito pelas Faculdades Integradas de Jaú - Fundação Educacional Dr. Raul Bauab. Professora de Educação Superior, Nível IV - Grau A, do quadro de pessoal da Universidade do Estado de Minas Gerais, Unidade Ituiutaba. Coordenadora do grupo de Pesquisa em Direito Constitucional Contemporâneo, Constitucionalismo Global e Globalização da Universidade do Estado de Minas Gerais (UEMG), jamile.calissi@uemg.br. Professora Titular no Mestrado Profissional em Direito e Gestão de Conflitos da Universidade de Araraquara (UNIARA), jgcalissi@uniara.edu.br. Professora das Faculdades Integradas de Jaú - Fundação Educacional Dr. Raul Bauab. Pós-Doutorado (em andamento) em Direito pela FDRB/USP.

${ }^{3}$ Doutorando pelo Programa de Pós-Graduação em Ciência, Tecnologia e Sociedade da Universidade Federal de São Carlos - PPGCTS-UFSCar. Mestrado em Direito com ênfase em Teoria do Direito e do Estado pela UNIVEM - Centro Universitário Eurípedes de Marília. Especialista em Direito Civil e Processual Civil pela UEL - Universidade Estadual de Londrina/PR. Professor das Faculdades Integradas de Jaú - Fundação Educacional Dr. Raul Bauab. Professor de Educação Superior, Nível IV - Grau A, do quadro de pessoal da Universidade do Estado de Minas Gerais, Unidade Ituiutaba. Coordenador do Grupo de Pesquisa NEDEEC Núcleo de Estudos de Direito Empresarial e Economia Circular da Universidade do Estado de Minas Gerais renato.montefusco@uemg.br.
} 
ABSTRACT: The legal business in the form of built to suit, a theme that is intended to be developed in this present work, is based on complex business contracts, which regulate a differentiated operation and establish countless rights and obligations freely agreed between the parties. This type of operation, already widely spread abroad, started to be recognized in Brazil due to the need for large projects to be installed in the country due to the heating and full development of the real estate sector. As it is a complex legal business and the signing of a contract is based on the private autonomy of the parties. This paper aims to demonstrate the legality of inserting an arbitration commitment clause in built-to-suit contracts as a way to ensure legal certainty in business, especially if we consider requests for revision of the contractual bases due to supervening facts, as in the case of Covid-19 pandemic or other economic crises. It is believed that arbitration as a means of resolving conflicts will lead to greater security in the particularities of the business, prevailing the established pre-established contractual provisions.

KEYWORDS: Juridic business; autonomy of will of the parties; arbitration; contracts; built to suit.

\section{INTRODUÇÃO}

O negócio jurídico denominado como built to suit conhecido e desenvolvido orginalmente nos Estados Unidos se popularizou no Brasil perto dos anos 2000, graças ao desenvolvimento econômico do país e devido ao forte aquecimento do mercado imobiliário, gerando oportunidade para a iniciativa privada explorar esse tipo de operação.

Assim, com a possibilidade das construtoras e incorporadoras captarem recursos financeiros no mercado de capitais e diante do crescimento das operações no setor imobiliário, grandes empreendimentos necessitavam de um local estrategicamente definido e com a obra desenvolvida, sem que seu capital fosse imobilizado em sua execução.

Diante disso, os contratos de built to suit passaram a ser aceitos no mercado imobiliário brasileiro. Entretanto, esse tipo de negociação somente foi regulamentado na legislação brasileira no ano de 2012, que inseriu essa modalidade de contratação na lei do Inquilinato.

Contudo, necessária a análise da legislação vigente, em virtude da liberdade de contratar nas situações em que ambas as partes são economicamente suficientes e entender a importância de um meio alternativo de solução de conflitos em detrimento da intervenção estatal, como forma de dirimir os efeitos de uma decisão judicial que poderá ser prejudicial a uma rede de partes inseridas no negócio e garantir a celeridade a eventuais conflitos. 
Nesse sentido, o presente trabalho desenvolve o conceito e evolução histórica dos contratos built to suit através da análise doutrinária e jurisprudencial.

Analisa, também, a lei de liberdade econômica e sua correlação com o objeto de estudo a partir de sua adoção na lei de locações.

Propõe, ainda, cláusula arbitral para resolução de conflitos que possam surgir após a adoção do contrato aqui estudado.

Por fim, para o desenvolvimento do presente trabalho foi utilizada pesquisa bibliográfica, além de jurisprudencial e, na escrita, o procedimento dedutivo. Justifica-se o presente estudo, pois, a partir dele, poderá ser possível a visualização de um panorama de gestão extrajudicial de conflitos que eventualmente possam surgir a partir dos contratos built to suit.

\section{EVOLUÇÃO HISTÓRICA DOS CONTRATOS DE BUILT TO SUIT}

A operação de Built to suit traduzido para o português como "operação de construção sob medida" ou "contrato de locação por encomenda" é uma operação que foi desenvolvida originalmente nos Estados Unidos e vem sendo muito explorada globalmente desde o ano de 1950.

Chegou ao Brasil perto dos anos 2000 em um momento de forte desenvolvimento no país, como um instrumento que permitisse efetivamente a exploração do capital econômico para fazer negócios imobiliários. À medida que o tempo foi passando a legislação foi se adaptando ao novo cenário a legislação foi se aperfeiçoando.

Com a evolução do sistema imobiliário e com a estabilidade econômica advinda do Plano Real foi uma grande conquista e fator determinante para o desenvolvimento do País, possibilitando o acesso ao mercado de capitais e o crescimento do poder aquisitivo da população trazendo a confiança necessária para a realização desse tipo de investimento (GOMES, 2019, p. 17).

Ainda, com a promulgação da Lei 9.514/1997, responsável pela implementação do Sistema de Financiamento Imobiliário (SFI) e pela alienação fiduciária de bens imóveis em 
garantia, possibilitou o crescimento das operações imobiliárias e a possibilidade de construtoras e incorporadoras captarem recursos financeiros no mercado de capitais, o que ocasionou maiores aproximações entre as instituições financeiras e o setor imobiliário.

Nesse sentido, a partir de 1997, o mercado imobiliário brasileiro estava aquecido e em pleno desenvolvimento o que ocasionou diversos ramos da economia desmobilizarem seus ativos, ocasionando uma alta procura de imóveis para locação por parte dos empreendedores imobiliários na aquisição de imóveis para posterior locação. (ZACARELLI, 2019, p. 15)

Nessa medida, os investimentos passaram a ser insuficientes, pois diante das complexidades das operações empresariais, necessitavam de construções peculiares, edificadas especialmente para cada especificidade. Assim, diante da necessidade de se ampliar as plantas industriais no país e atender as peculiaridades de cada empresa, surgiram aqui as operações denominadas built to suit.

\section{CONCEITO DE CONTRATO DE BUILT TO SUIT}

Os contratos de built to suit são contratos de longa duração, mediante o qual, uma das partes, o locatário, contrata a construção de um imóvel de acordo com suas especificidades e recebe do locador o edifício nos termos de sua encomenda. Trata-se de realização de grandes empreendimentos, realizados sob encomenda.

É interessante apresentar uma noção do que são os contratos de built to suit, conforme esclarece Luiz Antonio Scavone Junior:

O contrato de locação por encomenda (que inclui o contrato built-to-suit) é contrato de locação não residencial mediante o qual o locador ou alguém por ele, em razão de especificações descritas pelo locatário no contrato, leva a efeito aquisição, construção ou reforma do imóvel antes da ocupação, de acordo com as necessidades do locatário, submetendo o pacto à Lei do Inquilinato (2017, p. 1261).

No mesmo sentido, Rodrigo Ruete Gasparetto conceitua contrato built to suit como:

Trata-se de um negócio jurídico por meio do qual uma empresa contrata a outra usualmente do ramo imobiliário ou de construção, para identificar um terreno e nele construir uma unidade comercial ou industrial que atenda às exigências específicas da empresa contratante, tanto no que diz respeito à 
localização, como no que tange às características físicas da unidade a ser construída. Uma vez construída, tal unidade será disponibilizada, por meio de locação, à empresa contratante, por determinado tempo ajustado entre as partes (2011, p. 31).

Como visto, o contrato de built to suit decorre de um negócio jurídico em que uma das partes, o empreendedor imobiliário, reforma ou edifica um imóvel de acordo com as diretrizes transmitidas pelo ocupante que, ao final da obra, receberá por cessão o uso da edificação por determinado período (GOMIDE, 2017, p. 12).

Tomando por base a ideia trazida pelos autores e por se tratar de um contrato que traduz um investimento econômico que une interesses do investidor e do tomador do investimento. Define-se assim, como locador o dono do imóvel ou aquele que procura o terreno e que desenvolve sob medida o projeto cobrando um aluguel pelo uso da construção, para atender as necessidades do locatário, que se se obriga a indicar as características do imóvel de que precisa, passar as especificações das construções de que necessita e pagar o valor do aluguel, sendo este, o contratante do investimento.

Como se nota, o locador adquire um imóvel e sobre ele constrói algo nas exatas condições, termos e características que são demandadas pelo locatário. São desenvolvimentos de plantas industriais ou grandes edifícios comerciais, construção com determinadas características bem específicas. Vale ressaltar que esse tipo de operação é muito comum para atender grandes empreendimentos, como: fábricas de desenvolvimento do setor automotivo, centros de distribuição, hipermercados e frigoríficos.

\section{OS CONTRATOS DE BUILT TO SUIT NA LEI DE LOCAÇÕES}

O contrato de built to suit foi introduzido no ordenamento jurídico através da Lei 12.744/2012 que alterou o artigo $4^{\circ}$ da Lei de Locações (Lei 8.245/91) e incluiu o artigo 54-A regulamentando uma disposição específica a respeito desse tipo de operação.

Art. 54-A. Na locação não residencial de imóvel urbano na qual o locador procede à prévia aquisição, construção ou substancial reforma, por si mesmo ou por terceiros, do imóvel então especificado pelo pretendente à locação, a fim de que seja a este locado por prazo determinado, prevalecerão as condições livremente pactuadas no contrato respectivo e as disposições procedimentais previstas nesta Lei. (Incluído pela Lei $n^{\circ} 12.744$, de 2012) 
$\S 1$ 1o Poderá ser convencionada a renúncia ao direito de revisão do valor dos aluguéis durante o prazo de vigência do contrato de locação. (Incluído pela Lei $\mathrm{n}^{\circ} 12.744$, de 2012)

§ 2 o Em caso de denúncia antecipada do vínculo locatício pelo locatário, compromete-se este a cumprir a multa convencionada, que não excederá, porém, a soma dos valores dos aluguéis a receber até o termo final da locação.

Diferentemente de um contrato de locação comercial urbana, o contrato de built to suit possui algumas peculiaridades e se caracteriza pela cessão de imóvel construído de acordo com as necessidades do locatário, ou seja, a cessão temporária de uso de imóvel mediante pagamento de uma retribuição denominada aluguel e submetida à Lei do inquilinato. (SCAVONE JUNIOR, 2017, p. 1255)

Por mais que este tipo de contrato esteja inserido na lei do inquilinato este poderá ser livremente pactuado entre as partes seus termos e condições. A própria lei garante essa possibilidade. Da mesma forma, prevê a renúncia ao direito de revisão do valor dos alugueis durante a vigência do contrato, diferentemente do que ocorre nas locações comuns.

Dessa forma, o que diferencia o tratamento jurídico dado um contrato de locação comum de um de natureza built to suit é o maior prestígio à autonomia da vontade que deve ser conferido a este último, em detrimento do regramento geral previsto na Lei $\mathrm{n}^{\circ}$ 8.245/91.

Outrossim, havendo denúncia antecipada do contrato pelo locatário, este será responsável pela multa contratual convencionada pois tais disposições visam primordialmente garantir que o valor do aluguel mensal e o prazo do contrato privilegiem não só a contraprestação pelo uso do bem, mas, sobretudo, o retorno do investimento realizado no local pelo locador.

Por se tratar de um contrato paritário entre as partes, onde há liberdade de contratação e inexistência de desequilíbrio, pois aquele que busca um contrato de built to suit (locatário) poderá ser a parte mais forte na relação contratual em relação ao contratado (locador) que adquiriu um imóvel e desenvolveu a obra e que se torna credor por longos anos dos valores locatícios.

\section{DA TIPICIDADE DO CONTRATO DE BUILT TO SUIT}


Muito se discute acerca da tipicidade dos contratos de built to suit, anteriormente à introdução do artigo 54-A na Lei do Inquilinato, esse tipo de contrato era considerado atípico, pois não havia regulamentação específica na legislação para identificar seus elementos essenciais, e mesmo após o advento da Lei 12.744/12 ainda existe divergência doutrinária acerca da tipicidade desse tipo de contratação.

Dessa forma, entende-se por contratos típicos aqueles que recebem do ordenamento jurídico regulamentação específica em lei, e contratos atípicos aqueles que não possuem regramento próprio na legislação, podendo ser admitidos pelo legislador como resultado da liberdade de contratar, conforme preceitua o artigo 425 do Código Civil "É lícito às partes estipular contratos atípicos, observadas as normas gerais fixadas neste Código". (BRASIL, 2002)

$\mathrm{Na}$ linha de contratos atípicos, surgem, os chamados contratos atípicos mistos, que se originam de elementos próprios e combinam elementos de outros contratos, dando lugar a um novo tipo não disciplinado especificamente em lei, caracterizados pela própria vontade das partes em sua liberdade de contratar. (GOMES, 1994, p. 104)

Contratos mistos não correspondem a um único modelo típico, mas sim vários tipos que foram modificados, formando uma nova espécie contratual não prevista em lei. $\mathrm{Na}$ medida em que a operação de built to suit e sua estrutura combinam prestações típicas de um contrato de locação e também de empreiteira, insere um misto de elementos jurídicos típicos em um único contrato.

Para Luiz Antonio Scavone Junior (2017, p. 1257), os contratos de built to suit são típicos, pois sua abrangência foi ampliada através da Lei 12.744/12 que estabeleceu definição legal para o tema.

Em sentido contrário, Juliana Braido Zacarelli (2015, p. 24) é adepta ao posicionamento de contrato atípico misto, pelo fato de que às partes contratantes determinam as regras que serão aplicadas no desenvolvimento da relação contratual, até mesmo, na solução de eventuais conflitos que surjam no decorrer do cumprimento das obrigações contratuais. 
O entendimento acima também é defendido por Alexandre Gomide (2017, p. 55). Na opinião do autor os contratos de built to suit nunca poderão ser entendidos como apenas um contrato de locação simplesmente, isso porque, além da locação sempre terá a empreitada, denotando assim um contrato atípico misto. Argumenta ainda, que a Lei do Inquilinato não é suficiente para regular esse tipo de contrato em razão da complexidade que extrapola a mera locação comercial.

De fato, com a evolução jurisprudencial reconhecendo esse tipo de contratação e consolidando essa modalidade de negócio na legislação brasileira, e por se tratar de um contrato cujas várias particularidades possíveis determinam sua complexidade, se comparado a um contrato de locação comum, se faz necessário uma interpretação à luz dos princípios que norteiam as bases negociais devendo reconhecer o interesse das partes a época da contratação e observando as limitações estabelecidas na legislação competente para resultar em segurança jurídica as partes.

\section{DA APLICABILIDADE DA LEI DE LIBERDADE ECONÔMICA}

A liberdade econômica (Lei 13.874/19) e a autonomia privada da vontade das partes vêm sendo privilegiada nas relações contratuais e principalmente nas situações em que as partes são paritárias em ambas as pontas da negociação. O caput do artigo 54-A da Lei 8.245/91 assim define: "prevalecerão as condições livremente pactuadas no contrato respectivo e as disposições procedimentais previstas nesta Lei”.

Com base no princípio da autonomia privada que norteia o direito contratual significa dizer que as partes têm a liberdade de estabelecer as normas que serão aplicadas no negócio jurídico pactuado, desde que não ultrapasse as disposições legais cogentes (Lei do inquilinato), a boa-fé e a função social do contrato.

Neste vagar, verifica-se a importância da boa-fé objetiva, não podendo as partes afastar os deveres oriundos deste princípio, sendo incompatível com qualquer prática abusiva com intuito de impedir situações de abuso de direito. 
É evidente que se torna complicado discutir a intervenção do estado e a discussão de algumas cláusulas contratuais em que uma das partes tem a intenção de rever a própria declaração de vontade, como por exemplo, a revisão dos valores a título de aluguéis em decorrência do momento de excepcionalidade vivenciado através da pandemia, alegando o caso fortuito, força maior e a teoria da imprevisão.

Algumas decisões do Tribunal Paulista vêm privilegiando a questão da autonomia da vontade e a obrigatoriedade do cumprimento do contrato (pacta sun servanda):

PROCESSUAL CIVIL - SENTENÇA - NULIDADE - CERCEAMENTO DE DEFESA - NÃO OCORRÊNCIA - NULIDADE AFASTADA PRELIMINAR REPELIDA. O juiz é o destinatário da prova e deve decidir quais provas são relevantes à formação de sua convicção, a teor do disposto nos artigos 370 e 371, do Código de Processo Civil, sendo, no caso, dispensada a produção de prova pericial. LOCAÇÃO DE IMÓVEIS AÇÃO DECLARATÓRIA C.C. REVISIONAL PRETENSÃO DE REDUÇÃO DO VALOR DO ALUGUEL IMPERTINÊNCIA - AUSÊNCIA DE JUSTA CAUSA A JUSTIFICAR A INTERVENÇÃO JUDICIAL NO CONTRATO RECONHECIMENTO DO REGIME DE BUILT TO SUIT - OBRAS EXECUTADAS NOS IMÓVEIS ALUGADOS DE AMPLA REESTRUTURAÇÃO, COM DIVERSAS MELHORIAS REALIZADA PELA RÉ (LOCADORA) PARA PROPICIAR PLENO ATENDIMENTO À ATIVIDADE PROFISSIONAL DESEMPENHADA PELAS AUTORAS (LOCATÁRIAS) REVISÃO DAS CLÁUSULAS CONTRATUAIS EM RAZÃO DE PANDEMIA DESCABIMENTO - SENTENÇA MANTIDA RECURSO NÃO PROVIDO. Não trazendo a parte apelante fundamentos suficientes a modificar a sentença de primeiro grau, que reconheceu a ausência de justa causa a lastrear a intervenção judicial no contrato em apreço, mesmo diante de contexto mundial atípico, em razão de pandemia, sob pena de violar a autonomia da vontade, de rigor a manutenção integral da sentença, cujos fundamentos se adotam como razão de decidir. Classe/Assunto: Apelação Cível / Locação de Imóvel. Relator(a): Paulo Ayrosa. Comarca: Santos. Órgão julgador: $31^{\mathrm{a}}$ Câmara de Direito Privado. Data do julgamento: 06/11/2020. Data de publicação: 06/11/2020. Apelação $\mathrm{N}^{\circ} 1006728-08.2020 .8 .26 .0562$

APELAÇÃO CÍVEL - Locação - Imóvel não residencial - Embargos à Execução - Execução de título executivo extrajudicial lastreado em contrato de locação built to suit - Multa penal pela rescisão antecipada do contrato pela locatária - Sentença de improcedência dos embargos - Recurso das embargantes - Julgamento antecipado da lide - Cerceamento de defesa Inocorrência - Desnecessidade de dilação probatória - Prova literal acostada aos autos, suficiente para a formação do convencimento do Juízo a quo Locadora que não necessita comprovar os gastos com a construção do imóvel locado pela modalidade built to suit - Alegação de inexistência de título executivo extrajudicial - Afastamento - Contrato de locação - Título de obrigação líquida, certa e exigível - Dicção dos arts. 784, VIII e 783, ambos do CPC - Mérito - Cláusula expressa do contrato de locação que prevê 
pagamento de multa penal pela rescisão antecipada do contrato pela locatária, equivalente a $20 \%$ da soma dos alugueres faltantes para o término do contrato - Caracterização - Princípio pacta sunt servanda que vincula as partes no direito contratual - Inteligência do art. 54-A introduzido à Lei ${ }^{\circ}$ 8.245/91 pela Lei $n^{\circ} 12.744 / 2012$ e que modificou o art. $4^{\circ}$ da lei de locação - Cobrança da multa que tem fundamento legal e contratual - Verba honorária sucumbencial - Percentual estabelecido livremente pelas partes no contrato de locação, corretamente aplicada na planilha de débito pela exequente/embargada - Inexistência de cobrança de honorários contratuais Observação que se faz apenas por este acórdão, de ofício, para afastamento do percentual de mais $10 \%$ de verba honorária sucumbencial constante do dispositivo da sentença - Sentença mantida, com observação - RECURSO DESPROVIDO, com observação. Sem majoração dos honorários advocatícios em fase recursal, porquanto vedado ultrapassar o limite máximo previsto no art. 85, § 11, parte final, do CPC. (TJSP; Apelação Cível 1011093-55.2019.8.26.0008; Relator (a): Sergio Alfieri; Órgão Julgador: 28 Câmara de Direito Privado; Foro Regional VIII - Tatuapé - $2^{\text {a }}$ Vara Cível; Data do Julgamento: 04/11/2020; Data de Registro: 04/11/2020)

Relevante demonstrar que o artigo 54-A da Lei de Locações dispõe sobre a possibilidade de renúncia a algumas normas tidas como de ordem pública, como por exemplo, a revisional de alugueis, além disso, prevê também, se o contratante romper o contrato, diferentemente do que ocorre numa locação comum, ele pode, desde que previsto em contrato, ser condenado a pagar a indenização total pactuada.

Dessa forma, a intervenção estatal se dará de forma excepcional, quando de fato a situação demandar, pois a liberdade econômica só ratifica a vontade das partes que o artigo 54-A já deixou claro, trouxe clareza há alguns pontos que nas operações ainda geravam questionamentos e dúvidas. A Lei de liberdade econômica confirma a liberdade das partes em contratar em especial uma operação de built to suit, a intervenção do estado, a depender da situação poderá ser útil e até salvar determinada contratação quando necessária.

\section{DA CLÁUSULA COMPROMISSÓRIA ARBITRAL}

A busca de proteção do capital investido através da capitação de recurso investido implica necessariamente que os contratos de built to suit não possam ser lidos e interpretados como um negócio jurídico único e isolado, porque dele se derivam outros contratos que são 
relacionados em rede. Proteger o investimento criando mecanismos de desestímulo a uma rescisão antecipada do contrato protege também todas as partes ligadas ao negócio.

Assim, nesse tipo de contrato dado a paridade das partes, a tendência é de se privilegiar a autonomia das vontades e se optar pelos meios alternativos de solução de conflitos quando do surgimento de um conflito.

Uma saída, diante da natureza econômica do negócio e como forma de garantir celeridade à solução de eventuais conflitos insurgentes do negócio entabulado seria a inserção do procedimento arbitral (Lei 9.307/1996), um meio alternativo de solução de conflitos referentes a direitos patrimoniais disponíveis, perfeitamente possível nos casos de built to suit (SCAVONE JUNIOR, 2017, p. 1261).

Além da morosidade do Poder Judiciário, a estipulação de cláusula de compromisso arbitral nos contratos de built to suit visaria o objetivo de se manter o sigilo e a confidencialidade das condições negociadas entre as partes e não traria a público eventuais litígios decorrentes desse tipo de operação. É evidente a vantagem da inserção de cláusula de compromisso arbitral como forma de resolução de conflitos.

Nesse ínterim, importante o instituto da arbitragem que consiste em um modo extrajudicial de solução de conflitos, composto por um processo através do qual a contenda entre as partes é solucionada por terceiro(os) neutros e não pelo Poder Judiciário (DINAMARCO, 2013).

Trata-se de um método onde as partes prescindem do Poder Judiciário para solucionar o conflito. O processo de gestão do conflito é conduzido por um árbitro ou por um tribunal de arbitragem que atuam de modo imparcial.

O arbitro ou tribunal de arbitragem será de livre escolha das partes, assim como o procedimento.

A autonomia da vontade das partes mostra-se notória nesta escolha, ao contrário ao que aconteceria no Poder Judiciário, onde há a distribuição das petições por sorteio. O autor aclara que o arbitro é escolhido por seu vasto conhecimento sobre a temática, de forma prévia para resolver futura e eventual controvérsia entre as partes (RODOVALHO, 2015). 
A cláusula arbitral, escolha feita pelas partes para adoção do procedimento arbitral em caso de litígio, encontra-se prevista no artigo 4 da Lei de Arbitragem (Lei n. 9.307/1996), que assim dispõe:

Art. $4^{\circ}$ A cláusula compromissória é a convenção através da qual as partes em um contrato comprometem-se a submeter à arbitragem os litígios que possam vir a surgir, relativamente a tal contrato.

$\S 1^{\circ}$ A cláusula compromissória deve ser estipulada por escrito, podendo estar inserta no próprio contrato ou em documento apartado que a ele se refira.

$\S 2^{\circ}$ Nos contratos de adesão, a cláusula compromissória só terá eficácia se o aderente tomar a iniciativa de instituir a arbitragem ou concordar, expressamente, com a sua instituição, desde que por escrito em documento anexo ou em negrito, com a assinatura ou visto especialmente para essa cláusula.

A cláusula arbitral é uma convenção em um contrato onde as partes comprometem-se a submeter os eventuais litígios decorrentes de sua relação, ao procedimento extrajudicial da arbitragem.

É importante pontuar que, tanto a cláusula compromissória quanto o compromisso arbitral são elementos da arbitragem, nos termos o artigo 3 da Lei de Arbitragem: "as partes interessadas podem submeter a solução de seus litígios ao juízo arbitral mediante convenção de arbitragem, assim entendida a cláusula compromissória e o compromisso arbitral”.

Nesse sentido, ambos os institutos servem para deflagrar a arbitragem. Contudo, a cláusula compromissória é o ato consensual por meio do qual as partes decidem que futuras avenças serão submetidas ao juízo arbitral, e o compromisso arbitral é o ato consensual a partir do qual as partes decidem submeter um conflito atual, isto é, concreto, à arbitragem.

Enquanto a primeira está prevista no artigo 4 da Lei de Arbitragem, anteriormente citada, a segunda encontra fundamento no artigo 9 da mesma lei, in verbis:

Art. $9^{\circ} \mathrm{O}$ compromisso arbitral é a convenção através da qual as partes submetem um litígio à arbitragem de uma ou mais pessoas, podendo ser judicial ou extrajudicial.

$\S 1^{\circ} \mathrm{O}$ compromisso arbitral judicial celebrar-se-á por termo nos autos, perante o juízo ou tribunal, onde tem curso a demanda.

$\S 2^{\circ}$ O compromisso arbitral extrajudicial será celebrado por escrito particular, assinado por duas testemunhas, ou por instrumento público. 
Entende-se que para o contrato built to suit, a melhor opção seja a de cláusula compromissória arbitral, tendo em vista a possibilidade de sua estipulação já no próprio contrato de origem.

A cláusula arbitral compromissória pode ser de duas naturezas, a vazia e a cheia.

A cláusula arbitral compromissória vazia prescinde das indicações para a nomeação de árbitros em eventual litígio, o que obriga à notificação da parte para a instauração do juízo arbitral.

Art. $6^{\circ}$ Não havendo acordo prévio sobre a forma de instituir a arbitragem, a parte interessada manifestará à outra parte sua intenção de dar início à arbitragem, por via postal ou por outro meio qualquer de comunicação, mediante comprovação de recebimento, convocando-a para, em dia, hora e local certos, firmar o compromisso arbitral.

Parágrafo único. Não comparecendo a parte convocada ou, comparecendo, recusar-se a firmar o compromisso arbitral, poderá a outra parte propor a demanda de que trata 0 art. $7^{\circ}$ desta Lei, perante o órgão do Poder Judiciário a que, originariamente, tocaria o julgamento da causa.

Neste caso, a resolução da demanda observará o artigo 7 da Lei de Arbitragem que estabelece os parâmetros para a solução do problema, principalmente, se uma das partes apresentar resistência ao método adotado.

Art. $7^{\circ}$ Existindo cláusula compromissória e havendo resistência quanto à instituição da arbitragem, poderá a parte interessada requerer a citação da outra parte para comparecer em juízo a fim de lavrar-se o compromisso, designando o juiz audiência especial para tal fim.

$\S 1^{\circ} \mathrm{O}$ autor indicará, com precisão, o objeto da arbitragem, instruindo o pedido com o documento que contiver a cláusula compromissória.

$\S 2^{\circ}$ Comparecendo as partes à audiência, o juiz tentará, previamente, a conciliação acerca do litígio. Não obtendo sucesso, tentará o juiz conduzir as partes à celebração, de comum acordo, do compromisso arbitral.

$\S 3^{\circ}$ Não concordando as partes sobre os termos do compromisso, decidirá o juiz, após ouvir o réu, sobre seu conteúdo, na própria audiência ou no prazo de dez dias, respeitadas as disposições da cláusula compromissória e atendendo ao disposto nos arts. 10 e $21, \S 2^{\circ}$, desta Lei.

$\S 4^{\circ}$ Se a cláusula compromissória nada dispuser sobre a nomeação de árbitros, caberá ao juiz, ouvidas as partes, estatuir a respeito, podendo nomear árbitro único para a solução do litígio.

$\S 5^{\circ} \mathrm{A}$ ausência do autor, sem justo motivo, à audiência designada para a lavratura do compromisso arbitral, importará a extinção do processo sem julgamento de mérito.

$\S 6^{\circ}$ Não comparecendo o réu à audiência, caberá ao juiz, ouvido o autor, estatuir a respeito do conteúdo do compromisso, nomeando árbitro único. 
$\S 7^{\circ}$ A sentença que julgar procedente o pedido valerá como compromisso arbitral.

Finalmente, a cláusula compromissória cheia, que institui todas as condições necessárias para a arbitragem em caso de litígio. Assim, por exemplo, estipula como deve ser escolhido o árbitro, quais as normas a serem aplicadas e o local em que ocorrerá arbitragem dentre outras previsões. Assim, tudo o que tenha sido estipulado nessa cláusula será, obrigatoriamente, observado na sentença de homologação (CÂMARA, 2007).

\section{CONSIDERAÇÕES FINAIS}

Os contratos de built to suit estão cada vez mais sendo utilizados no Brasil, principalmente em decorrência do forte crescimento imobiliário e da necessidade dos grandes empreendimentos ampliarem seus negócios no país.

Assim, por se tratar de um negócio jurídico empresarial, por meio do qual um contratante, também denominado de locatário contrata uma empresa do ramo de construção ou não, aqui chamado de locador, para que este, em razão das especificações descritas pelo locatário no contrato, identifique um terreno e nele construa uma unidade comercial ou industrial que atenda às exigências específicas da empresa contratante. Submetendo o pacto às regras da Lei do Inquilinato.

Uma vez construída, tal unidade será disponibilizada a empresa contratante/locatário, por meio de locação, por determinado tempo ajustado entre as partes, pagando o valor do aluguel convencionado entre as partes.

Ademais, a legislação foi se adaptando e esse tipo de operação foi regulamentada pelo artigo 54-A da Lei do inquilinato (Lei 8.245/91) que dispõe especificamente a respeito desse tipo de operação.

Ante a possibilidade de se privilegiar a autonomia da vontade das partes e estabelecer livremente as condições pactuadas, principalmente por se tratar de um contrato com paridade de partes, não devendo esquecer deve-se observar a importância da boa-fé objetiva e da 
função social do contrato, como forma de impedir a inserção de normas que ultrapasse as disposições legais cogentes.

Nesse sentido, verifica-se a importância de se observar os princípios contratuais que regem os negócios jurídicos para tentar evitar a intervenção estatal, já que o intuito desse tipo de contratação é reduzir ao máximo a intervenção judicial na relação contratual, privilegiando a autonomia da vontade das partes optando pelos meios alternativos de solução de conflitos, em especial pelo procedimento arbitral dado a paridade entre as partes nessas grandes negociações.

Para tanto, a arbitragem mostra-se como um procedimento adequado para adoção prévia em contrato, através de cláusula arbitral compromissória cheia, oportunizando às partes o estabelecimento de regras específicas a serem utilizadas caso haja conflito oriundo do negócio aprazado. Tem por objetivo final, a possibilidade de resolução de eventual conflito sem a participação do Poder Judiciário, estabelecendo-se, assim, a autonomia dos participantes, bem como, a resolução mais célere em caso de conflito.

Por fim, entende-se que o contrato aqui estudado pode e deve conter cláusula arbitral compromissória, tendo em vista a praticidade que essa previsão pode estabelecer na relação pactuada, caso haja um conflito futuro que necessite de intervenção.

\section{REFERÊNCIAS BIBLIOGRÁFICAS}

BRASIL. Lei $\mathrm{n}^{\circ}$ 9.514, de 20 de novembro de 1997. Dispõe sobre o Sistema de Financiamento Imobiliário, institui a alienação fiduciária de coisa imóvel e dá outras providências. Disponível em: $<$ http://www.planalto.gov.br/ccivil_03/leis/19514.htm 28.07.2021>. Acesso: 28 jul. 2021.

BRASIL. lei no 10.406, de 10 de janeiro de 2002. Institui o Código Civil. Disponível em:< http://www.planalto.gov.br/ccivil_03/leis/2002/110406compilada.htm>. Acesso: 19 set. 2021.

BRASIL. Lei $\mathrm{n}^{\circ}$ 12.744, de 19 de dezembro de 2012. Altera o art. $4^{\mathbf{0}}$ e acrescenta art. 54-A à Lei $\mathbf{n}^{0}$ 8.245, de 18 de outubro de 1991, que “dispõe sobre as locações dos imóveis urbanos e os procedimentos a elas pertinentes", para dispor sobre a locação nos 
contratos de construção $\quad$ ajustada. Disponível em:<http://www.planalto.gov.br/ccivil 03/ ato2011-2014/2012/lei/112744.htm>. Acesso: 28.07.2021

BRASIL. Lei no 8.245, de 18 de outubro de 1991. Dispõe sobre as locações dos imóveis urbanos e os procedimentos a elas pertinentes. Disponível em:<http://www.planalto.gov.br/ccivil 03/leis/18245.htm. 28.07.2021>. Acesso: 28 jul. 2021.

BRASIL. Lei $n^{\circ}$ 13.874, de 20 de setembro de 2019. Institui a Declaração de Direitos de Liberdade Econômica; estabelece garantias de livre mercado; altera as Leis nos 10.406, de 10 de janeiro de 2002 (Código Civil), 6.404, de 15 de dezembro de 1976, 11.598, de 3 de dezembro de 2007, 12.682, de 9 de julho de 2012, 6.015, de 31 de dezembro de 1973, 10.522, de 19 de julho de 2002, 8.934, de 18 de novembro 1994, o Decreto-Lei $n^{\circ}$ 9.760, de 5 de setembro de 1946 e a Consolidação das Leis do Trabalho, aprovada pelo DecretoLei $n^{\circ}$ 5.452, de $1^{\circ}$ de maio de 1943; revoga a Lei Delegada $n^{\circ}$ 4, de 26 de setembro de 1962, a Lei $\mathrm{n}^{\mathrm{0}}$ 11.887, de 24 de dezembro de 2008, e dispositivos do Decreto-Lei $\mathrm{n}^{\circ}$ 73, de 21 de novembro de 1966; e dá outras providências. Disponível em:<http://www.planalto.gov.br/ccivil_03/_ato2019-2022/2019/lei/L13874.htm>. Acesso: 28 jul. 2021.

CÂMARA, Alexandre Freitas de. Arbitragem: Lei 9307/96. Rio de Janeiro, Lumen Juris, 2009.

DINAMARCO, Cândido Rangel. A arbitragem na teoria geral do processo. Malheiros Editores, 2013.

GASPARETTO, Rodrigo Ruete. Contratos built to suit. São Paulo: Fábrica de Livros, 2011.

GOMES, Daniel Cardoso. Contratos built to suit: novas perspectivas em face da lei $\mathbf{n}^{\mathbf{0} 12.744 / 2012}$. 2 ed. Rio de Janeiro: Lumen Juris, 2019.

GOMES, Orlando. Contratos. 14. ed. Rio de Janeiro: 1994

GOMIDE, Alexandre Junqueira. Contratos built to suit: aspectos controvertidos decorrentes de uma nova modalidade contratual. São Paulo: Revista dos Tribunais, 2017. 
Disponível em: $<$ https://www.teses.usp.br/teses/disponiveis/2/2131/tde-18122020-132305/ptbr.php > DOI: 10.11606/D.2.2017.tde-18122020-132305>. Acesso: 21 jul. 2021.

RODOVALHO, Thiago. Aspectos introdutórios da arbitragem. MANUAL de arbitragem para advogados. Brasília: Confederação das Associações Comerciais e Empresariais do Brasil, p. 10-17, 2015.

SCAVONE JUNIOR. Luiz Antonio. Direito imobiliário - Teoria e prática. $12^{\mathrm{a}}$ ed. - rev., atual. e ampl. - Rio de Janeiro: Forense, 2017.

TRIBUNAL DE JUSTIÇA DO ESTADO DE SÃO PAULO. Apelação Cível / Locação de Imóvel. Relator(a): Paulo Ayrosa. Comarca: Santos. Órgão julgador: $31^{\text {a }}$ Câmara de Direito Privado. Data do julgamento: 06/11/2020. Data de publicação: 06/11/2020. Disponível em: $<$ https://esaj.tjsp.jus.br/cjsg/resultadoCompleta.do. Acesso: 21 jul. 2021.

TRIBUNAL DE JUSTIÇA DO ESTAdO DE SÃO PAUlO. Apelação Cível 101109355.2019.8.26.0008; Relator (a): Sergio Alfieri; Órgão Julgador: $28^{\text {a }}$ Câmara de Direito Privado; Foro Regional VIII - Tatuapé - 2 ${ }^{\mathrm{a}}$ Vara Cível; Data do Julgamento: 04/11/2020. Disponível em: $<$ https://esaj.tjsp.jus.br/cjsg/resultadoCompleta.do $>$. Acesso: 30 jul. 2021

ZACARELLI, Juliana Braido. A INTERVENÇÃO JUDICIAL NOS CONTRATOS BUILT TO SUIT. INSPER. LL.M Direito dos Contratos. SÃO PAULO 2019. Disponível em:< http://dspace.insper.edu.br/xmlui/handle/11224/2509 >. Acesso 02 jul. 2021. 